\title{
Production of cloned mice using oocytes derived from ICR- outbred strain
}

\author{
Yoshiaki Tanabe¹, Hiroki Kuwayama', Sayaka Wakayama², Hiroaki Nagatomo³, \\ Masatoshi Ooga ${ }^{1}$, Satoshi Kamimura ${ }^{1}$, Satoshi Kishigami ${ }^{1,2}$ and Teruhiko Wakayama ${ }^{1,2}$ \\ ${ }^{1}$ Faculty of Life and Environmental Sciences, University of Yamanashi, Yamanashi, Japan, ${ }^{2}$ Advanced Biotechnology \\ Center, University of Yamanashi, Yamanashi, Japan and ${ }^{3}$ COC Promotion Center, University of Yamanashi, \\ Yamanashi, Japan \\ Correspondence should be addressed to T Wakayama; Email: twakayama@yamanashi.ac.jp
}

\begin{abstract}
Recently, it has become possible to generate cloned mice using a somatic cell nucleus derived from not only F1 strains but also inbred strains. However, to date, all cloned mice have been generated using F1 mouse oocytes as the recipient cytoplasm. Here, we attempted to generate cloned mice from oocytes derived from the ICR-outbred mouse strain. Cumulus cell nuclei derived from BDF1 and ICR mouse strains were injected into enucleated oocytes of both strains to create four groups. Subsequently, the quality and developmental potential of the cloned embryos were examined. ICR oocytes were more susceptible to damage associated with nuclear injection than BDF1 oocytes, but their activation rate and several epigenetic markers of reconstructed cloned oocytes/ embryos were similar to those of BDF1 oocytes. When cloned embryos were cultured for up to 4 days, those derived from ICR oocytes demonstrated a significantly decreased rate of development to the blastocyst stage, irrespective of the nuclear donor mouse strain. However, when cloned embryos derived from ICR oocytes were transferred to female recipients at the two-cell stage, healthy cloned offspring were obtained at a success rate similar to that using BDF1 oocytes. The ICR mouse strain is very popular for biological research and less expensive to establish than most other strains. Thus, the results of this study should promote the study of nuclear reprogramming not only by reducing the cost of experiments but also by allowing us to study the effect of oocyte cytoplasm by comparing it between strains.

Reproduction (2017) 154 859-866
\end{abstract}

\section{Introduction}

Although the successful production of cloned animals using somatic cell nuclear transfer is a promising technology with several potential applications in basic research, medicine and agriculture (Yang et al. 2007), the low success rate of cloning is a major obstacle to the widespread use of this technology (Thuan et al. 2010). Since the first cloned adult mammal was born (Wilmut et al. 1997), many studies have focused on modifying the cloning procedure. For example, in the mouse studies, technical improvement (Wakayama et al. 1998, 2016, Kishikawa et al. 1999, Boiani et al. 2003, Terashita et al. 2012) and selecting the optimal donor cell type (Wakayama \& Yanagimachi 2001, Inoue et al. 2003, Thuan et al. 2010, Mizutani et al. 2016, Kuwayama et al. 2017) were reported; however, most of them failed to improve the success rate of producing cloned offspring. A major breakthrough in this context occurred when epigenetic abnormalities were corrected using the histone deacetylase inhibitor (HDACi) trichostatin A (TSA) (Kishigami et al. 2006), which increased the success rate by up to six times compared with the success rate of the original method. Using several types of $\mathrm{HDACi}$, we can now produce cloned mice from several inbred strains for which this was not previously possible (Kishigami et al. 2007, Van Thuan et al. 2009, Ono et al. 2010, Thuan et al. 2010). The reprogramming potential of somatic cell nuclei derived from inbred strains is probably lower or is associated with certain obstacles compared with that of F1 somatic cell nuclei.

However, it remains unclear whether the reprogramming potential of oocyte cytoplasm differs among mouse strains. For example, oocyte composition, particularly the protein level, is a proxy for reprogramming ability; this is a key factor for the success of cloning. This concept led to the pursuit of the so-called reprogrammome (Pfeiffer et al. 2011), which may differ among oocytes of inbred mouse strains (Pfeiffer et al. 2015). Previously, it was demonstrated that the protein composition of oocyte of different mouse strains was different and these differences correlated with following embryonic developmental differences 
(Latham 1994). Recently, a quantitative proteomics analysis was performed, and more than thousands of proteins in mouse oocytes were identified (Wang et al. 2010, Ma et al. 2013, Pfeiffer et al. 2015). These reports suggested that the potential of oocytes of different strains was clearly different and it influences the features of embryos. Comparing the success rate of full-term cloning when oocytes are supplied from different inbred strains, factors for the successful reprogramming of oocyte cytoplasm could be successfully identified.

However, when several inbred mice oocytes, such as $\mathrm{C} 57 \mathrm{BL} / 6, \mathrm{DBA} / 2$ or $129 / \mathrm{Sv}$, were used as nuclear recipients, most of them developed to the two-cell stage, but only few cloned embryos developed to the blastocyst stage (Wakayama \& Yanagimachi 2001, Gao et al. 2004, Pfeiffer et al. 2015). The reason for this poor developmental potential of cloned embryos is unclear, but it is likely that the ability to develop to the blastocyst depends on the oocyte composition of the mouse strain. Yen et al. reported that the amount of several reprogramming factors in mouse oocytes was different among mouse strains (Yan et al. 2010). In addition, it is not surprising because even in normal fertilized embryos, the developmental potential in vitro was always found to be lower in inbred embryos than in F1 embryos. Therefore, to the best of our knowledge, to date, all cloned mice have been generated from F1 mouse oocytes (Wakayama \& Yanagimachi 2001, Gao et al. 2003, Inoue et al. 2003).

On the other hand, it is well known that outbred strains, such as ICR (CD-1), are less expensive to establish compared with inbred or F1 mouse strains, which is an important factor for a large number of experiments, particularly in small laboratories. Previously, it was thought that ICR mice were not the appropriate strains for the study of embryos in vitro, but the CZB medium was developed to overcome this obstacle (Chatot et al. 1990). The rate of cloning success by the original nuclear transfer method using F1 oocytes is approximately 2\% (Thuan et al. 2010). Therefore, compared with F1 oocytes, if the original nuclear transfer method was used on ICR oocytes, the success rate would probably be much lower; in other words, it is extremely unlikely that cloned offspring would be obtained. However, recent improvements in mouse cloning techniques have suggested that these obstacles may not be insurmountable. Specifically, if the newest method is used, it may be possible to produce cloned mice from inbred or outbred oocytes instead of F1 oocytes. Therefore, in this study, we examined the possibility of using recipient oocytes from the ICRoutbred mouse strain.

\section{Materials and methods}

\section{Animals}

ICR and B6D2F1 (C57BL/6×DBA/2) mice, aged 8-10 weeks, were used to produce oocytes, spermatozoa and cumulus cells.
The surrogate pseudopregnant females used as embryo transfer recipients were ICR strain mice mated with vasectomized males of the same strain. BD129F1 (B6D2F1 ×129/Sv) mice were used to collect cumulus cells as donor cells. B6D2F1 and ICR mice were purchased from Shizuoka Laboratory Animal Center (Hamamatsu, Japan). The BD129F1 strain was bred in our mouse facility. On the day of the experiments or after having finished all experiments, mice were euthanized by $\mathrm{CO}_{2}$ inhalation or by cervical dislocation and used for experiments. All animal experiments conformed to the Guide for the Care and Use of Laboratory Animals and were approved by the Institutional Committee of Laboratory Animal Experimentation of the University of Yamanashi.

\section{Collection of oocytes and cumulus cells}

Mature oocytes were collected from the oviducts of 8-10-weekold female mice that had been induced to superovulate with $5 \mathrm{IU}$ pregnant mare serum gonadotropin (Teikokuzoki, Tokyo, Japan) followed by $5 \mathrm{IU}$ human chorionic gonadotropin (Teikokuzoki) $48 \mathrm{~h}$ later. Cumulus-oocyte complexes (COCs) were collected from the oviducts approximately $16 \mathrm{~h}$ after hCG injection. After collection, COCs were placed in HEPESbuffered CZB medium (H-CZB) (Chatot et al. 1990) and treated with $0.1 \%$ bovine testicular hyaluronidase (Sigma-Aldrich). After several minutes, the cumulus-free oocytes were washed twice and then moved to a droplet of CZB medium for culture. At the same time, the remaining cumulus cells were introduced into the PVP medium (Kimura \& Yanagimachi 1995) on the manipulation chamber.

\section{Somatic cell nuclear transfer}

Groups of oocytes were transferred into a droplet of $\mathrm{H}-\mathrm{CZB}$ containing $5-\mathrm{mg} / \mathrm{mL} \mathrm{CB}$ on the microscope stage for enucleation of the metaphase II (MII) spindle. Oocytes undergoing microsurgery were held with a holding pipette and a hole was made in the zona pellucida following the application of several piezo-pulses (Prime Tech, Ibaraki, Japan) to an enucleation pipette. The MII chromosome-spindle complex was aspirated into the pipette with a minimal volume of ooplasm. After enucleation of all oocytes in one group, they were transferred into the CZB medium. For nuclear injection, donor cumulus cells were gently aspirated in and out of the injection pipette until their nuclei were largely devoid of visible cytoplasmic membrane. Each nucleus was immediately injected into an enucleated oocyte. Those reconstructed oocytes were kept in the incubator until activation.

In this study, cumulus cell nuclei collected from BDF1 and ICR mice were injected into oocytes collected from BDF1 and ICR mice to create four groups. In addition, BD129F1 cumulus cell nuclei were injected into BDF1 and ICR oocytes to confirm the results using different donor strains.

\section{Production of fertilized embryos by intracytoplasmic sperm injection (ICSI)}

ICSI was performed as described previously (Kimura \& Yanagimachi 1995). The sperm head derived from an ICR male 
mouse was separated from the tail by the application of several piezo-pulses, and the head was then injected into the oocyte derived from an ICR female mouse. After $10 \mathrm{~min}$ of recovery at room temperature, the oocyte was cultured in the CZB medium for preimplantation development.

\section{Immunostaining}

Embryos at $10 \mathrm{~h}$ after activation were fixed in PBS containing $4 \%$ paraformaldehyde and $0.2 \%$ (v/v) Triton X-100 (Nacalai Tesque, Kyoto, Japan) for $20 \mathrm{~min}$. The fixed oocytes were washed twice in PBS containing $0.25 \%$ (w/v) BSA (Nacalai Tesque) (PBS-BSA) for $15 \mathrm{~min}$ each. Embryos were then incubated with the primary antibodies: rabbit polyclonal anti-acH3K14 (1:100 dilution; Upstate Biotechnology Inc.), mouse monoclonal anti-H3K9me2 (1:100 dilution; Abcam Inc.) or rabbit monoclonal anti-H3K4me2 (1:100 dilution; Abcam Inc.) in PBS-BSA overnight at $4{ }^{\circ} \mathrm{C}$. After the embryos had been washed twice in PBS-BSA for 15 min each time, they were incubated for $1 \mathrm{~h}$ with dyeconjugated secondary antibodies: Alexa-Fluor 488-labeled goat anti-mouse IgG (Molecular Probes Inc) or AlexaFluor 488-labeled goat anti-rabbit IgG (Molecular Probes Inc.) at $25^{\circ} \mathrm{C}$. After washing the embryos twice in PBSBSA, they were mounted on a glass slide in Vectashield antibleaching solution (Vector Laboratories, Burlingame, CA, USA) containing 3- $\mathrm{gg} / \mathrm{mL}$ DAPI (Molecular Probes Inc.). Subsequently, serial images were obtained using fluorescence confocal microscopy (FV-1200; Olympus Corp.). Relative acH3K14, H3K9me2 and H3K4me2 levels in embryos were measured using Olympus Fluor View (Olympus).

\section{Activation of reconstructed oocytes and embryo transfer}

Reconstructed oocytes were activated using $5 \mathrm{mM} \mathrm{SrCl}_{2}$ in the $\mathrm{Ca}^{2+}$-free $\mathrm{CZB}$ medium in the presence of $50 \mathrm{nM}$ TSA supplemented with $5 \mu \mathrm{M}$ LatA for $10 \mathrm{~h}$ and then cultured in CZB until embryo transfer. The next day, the cloned embryos that had reached the two-cell stage were transferred into the oviducts of pseudopregnant ICR strain female mice at 0.5 days post-coitum ( $\mathrm{dpc}$ ). These mice had been mated with a vasectomized male the night before transfer and anesthetized using a peritoneal injection of Avertin just before the embryo transfer. At $19.5 \mathrm{dpc}$, the offspring were delivered by Cesarean section, and cloned pups were transferred to the cage of a naturally delivered foster mother.

\section{Statistical analysis}

The survival rate of injected oocytes, blastocyst formation rate, offspring development rate and body and placental weights were evaluated using Chi-squared tests. Fluorescence levels were evaluated using Student's $t$-test, and $P<0.05$ was considered to represent a statistically significant difference.

\section{Results}

\section{Manipulation of ICR oocytes as a recipient for nuclear transfer}

ICR oocytes were slightly more transparent and had fewer small granules inside the cytoplasm than BDF1 oocytes (Fig. 1A). Although the metaphase bump of ICR oocytes was not obvious, the MII spindle could
A

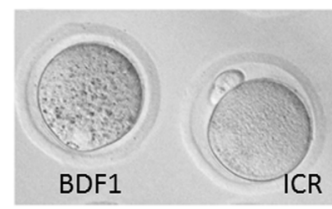

B

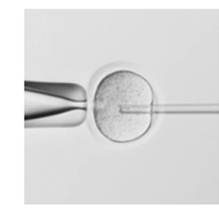

C

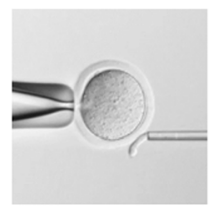

D

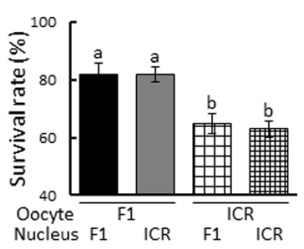

E

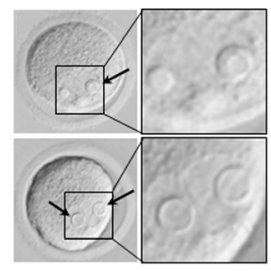

$\mathrm{F}$

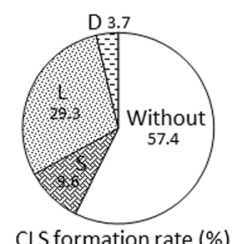

G

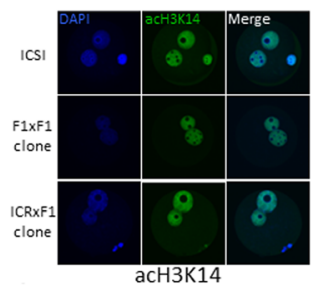

$\mathrm{H}$

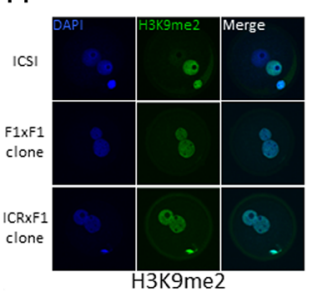

I

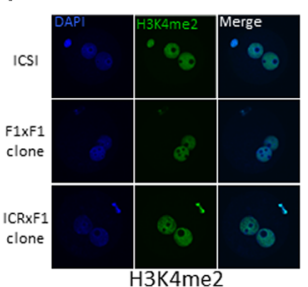

$\mathrm{J}$

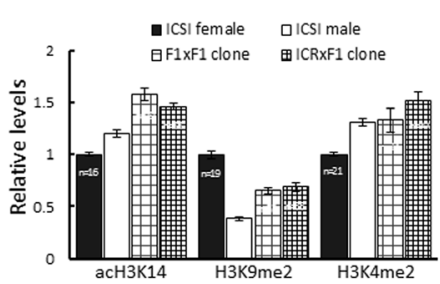

Figure 1 Nuclear transfer using ICR oocytes and epigenetic status of cloned embryos. (A) Comparison of oocytes between F1 and ICR. (B) Before enucleation. (C) After enucleation. (D) Survival rate of oocytes after nuclear injection. The survival rate was significantly decreased when ICR oocytes were used. (E) Cavity-like structure (CLS) in cloned embryos using ICR oocytes. (F) The CLS formation rate was examined. Without: CLS did not occur. S: A single small CLS. L: A single large CLS. D: Two small CLSs. (G, H, I and J) Histone modification in one-cell-stage embryos. (G) acH3K14, (H) H3K9me2 and (I) H3K4me2 levels in ICSI embryos and cloned embryos derived from F1 or ICR oocytes. (J) The intensities of immunofluorescence for acH3K14, H3K9me2 and H3K4me2 relative to those of DAPI. These were compared with the intensities in ICSIgenerated control embryos. The acetylation or methylation levels in these regions did not differ between cloned embryos derived from $\mathrm{F} 1$ and ICR oocytes. 
be easily identified by its color and hardness, and these oocytes could be easily enucleated, similar to BDF1 oocytes (Fig. 1B and C). When donor nuclei were injected into enucleated ICR oocytes, the survival rate decreased significantly compared with that of F1 oocytes, irrespective of the donor mouse strain (Fig. 1D). However, the activation rate and pronuclear formation rate of reconstructed ICR oocytes were similar to those of F1 oocytes (Table 1).

\section{Cavity-like structure (CLS) in nucleolus precursor body (NPB)}

Six hours after activation, most reconstructed ICR oocytes formed a pseudopronucleus, irrespective of the donor mouse strain. However, we noticed that nearly half $(43 \%)$ of the cloned embryos demonstrated a CLS inside the NPB (Fig. 1E), irrespective of the donor strain, but this did not occur when $F_{1}$ oocytes were used (Table 2). The size or number of CLS inside the NPB varied among the cloned zygotes. We categorized each zygote as having a small, large, double or no CLS, and then examined the capacity of these different zygotes to develop to blastocysts (Fig. 1F, Table 2). Although there were different numbers of zygotes in each of these categories, the rate of development to blastocysts did not differ among them and was similar to that in the group without CLS. This phenomenon was not observed in ICR-fertilized (ICSI) embryos, but approximately $30 \%$ of the parthenogenetically activated oocytes demonstrated CLS formation similar to that in ICR-cloned embryos (Table 2).

\section{Epigenetic similarity of cloned embryos between ICR and $F 1$ oocytes}

Cloned embryos exhibit several epigenetic differences compared with those exhibited by fertilized embryos (Wang et al. 2007, Terashita et al. 2013). Here, we investigated whether the cloned embryos generated from ICR oocytes also exhibited epigenetic differences compared with those exhibited by fertilized embryos and, if so, whether the differences were similar to those of embryos derived from F1 oocytes. To investigate this, cloned embryos derived from ICR or F1 oocytes and fertilized embryos were fixed at the pronuclear stage and immunostained with antibodies to acetylated histone $\mathrm{H} 3$ at lysine 14 (acH3K14) (Fig. 1G) and to dimethylated histone $\mathrm{H} 3$ at lysine 4 and 9 (H3K4me2 and H3K9me2) (Fig. $1 \mathrm{H}$ and $\mathrm{I}$ ). As shown in Fig. 1J, the acetylation and methylation levels did not differ between cloned embryos derived from ICR and from F1 oocytes, but were abnormally high or low, respectively, compared with those of control-fertilized embryos.

\section{In vitro development of cloned embryos derived from ICR oocytes}

When these cloned embryos were cultured for up to 5 days, the developmental rate at each stage was decreased in embryos derived from ICR oocytes $(24.6 \%-$ $30.0 \%)$ compared with that in embryos derived from F1 oocytes $(71.4 \%-79.1 \%)$, irrespective of the donor mouse strain (Fig. 2A and B, Table 1). When the cloned blastocysts derived from ICR oocytes were transferred into the uteri of female recipients, none of the embryos developed to full term. On the other hand, in a control experiment in which ICR oocytes fertilized with ICR spermatozoa were cultured in vitro for 4 days, $75.6 \%$ of them developed to blastocysts (Table 2).

\section{Full-term development of cloned embryos derived from ICR oocytes}

To test whether ICR oocytes can be used to generate cloned mice, cloned embryos derived from ICR or F1 oocytes were transferred to surrogate mothers. As shown in Table 3, approximately $80 \%$ of cloned embryos could develop to the two-cell stage, irrespective of the type of oocyte or donor nucleus (Fig. 2C). Subsequently, these two-cell embryos were transferred to the oviduct of female recipients. Consequently, healthy cloned mice were obtained (Fig. 2D) from all groups, and the birth rate was slightly lower using ICR oocytes (1.9\%) than using F1 oocytes $(2.6 \%)$, but the difference was not significant (Table 3). We attempted to confirm these results using another mouse strain, BD129F1, as a nuclear donor; the cumulus cells of this strain are known to have a higher

Table 1 In vitro development of cloned embryos derived from ICR oocytes.

\begin{tabular}{|c|c|c|c|c|c|c|c|c|c|c|}
\hline \multicolumn{2}{|c|}{ Mouse strain } & \multirow[b]{2}{*}{$\begin{array}{c}\text { No. of enucleate } \\
\text { oocytes }\end{array}$} & \multirow{2}{*}{$\begin{array}{l}\text { No. of oocytes } \\
\text { surviving after } \\
\text { injection }\end{array}$} & \multirow{2}{*}{$\begin{array}{l}\text { No. of oocytes } \\
\text { surviving after } \\
\text { activation }\end{array}$} & \multicolumn{6}{|c|}{ No. of embryos developed to } \\
\hline Oocyte & Nucleus & & & & PN & Fragment & One-cell & Two-cell & 4-8-cell & Morula/blastocyst (\%)* \\
\hline BDF1 & BDF1 & 264 & $206^{\mathrm{a}}$ & 204 & 196 & 18 & 3 & 17 & 26 & $140(71.4)^{\mathrm{a}}$ \\
\hline BDF1 & ICR & 272 & $219^{a}$ & 216 & 201 & 20 & 3 & 10 & 24 & $159(79.1)^{\mathrm{a}}$ \\
\hline ICR & BDF1 & 477 & $316^{\mathrm{b}}$ & 313 & 301 & 49 & 11 & 50 & 129 & $74(24.6)^{b}$ \\
\hline ICR & ICR & 476 & $300^{\mathrm{b}}$ & 299 & 290 & 50 & 10 & 33 & 117 & $87(30.0)^{b}$ \\
\hline
\end{tabular}

a vs b: $P<0.05$.

$\mathrm{PN}$ : pronucleus. 
Table 2 Cavity-like structure formation in ICR oocytes after nuclear transfer or activation.

\begin{tabular}{|c|c|c|c|c|c|c|c|c|}
\hline \multirow[b]{2}{*}{ Oocyte strain } & \multirow[b]{2}{*}{ Type of zygote } & \multirow[b]{2}{*}{ Cavity } & \multicolumn{6}{|c|}{ No. of embryos developed to } \\
\hline & & & $\begin{array}{c}\text { Pronuclear } \\
\text { formation }\end{array}$ & Fragment & One-cell & Two-cell & 4-8-cell & Morula/blastocyst (\%)* \\
\hline \multirow[t]{4}{*}{ ICR } & Clone & Without & $155(57.4)$ & 4 & 5 & 33 & 43 & $70(45.2)^{\mathrm{a}}$ \\
\hline & & Small & $26(9.6)$ & 0 & 1 & 2 & 8 & $15(57.7)^{\mathrm{a}}$ \\
\hline & & Large & $79(29.3)$ & 4 & 5 & 18 & 23 & $28(35.4)^{\mathrm{a}}$ \\
\hline & & Double & $10(3.7)$ & 0 & 1 & 1 & 5 & $3(30.0)^{\mathrm{a}}$ \\
\hline F1 & & Without & $49(100)$ & 1 & 0 & 1 & 3 & $44(89.8)^{b}$ \\
\hline \multirow[t]{4}{*}{ ICR } & Partheno & Without & $100(69.9)$ & 0 & 0 & 0 & 6 & $94(94.7)$ \\
\hline & & Small & $7(4.9)$ & 0 & 0 & 0 & 0 & $7(100)$ \\
\hline & & Large & $23(16.1)$ & 0 & 0 & 0 & 2 & $21(92.1)$ \\
\hline & & Double & $13(9.1)$ & 1 & 0 & 0 & 2 & $10(90.9)$ \\
\hline ICR & ICSI & Without & 127 & 0 & 0 & 6 & 25 & $96(75.6)$ \\
\hline
\end{tabular}

a vs b: $P<0.05$.

Partheno: Parthenogenetic.

cloning success rate than those of other strains (Ono et al. 2010, Wakayama et al. 2013). When the cumulus cell nuclei were injected into ICR or F1 enucleated oocytes, the success rate of obtaining cloned mice was $6 \%$ or $14 \%$, respectively (Table 3 ).
The mean body weight and placenta weight are shown in Fig. 2E and F. The cloned offspring obtained using ICR mice as a nuclear donor were slightly heavier than those obtained using F1 mice, irrespective of the oocyte strain; no such difference was observed between the weights
A

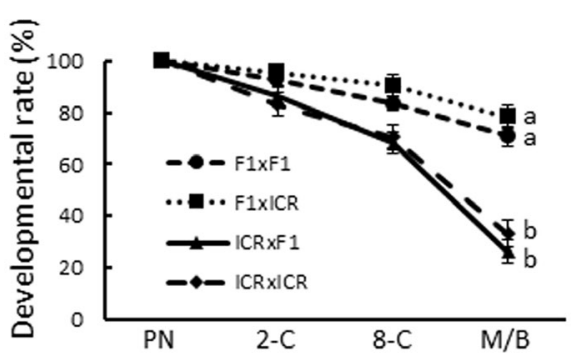

D

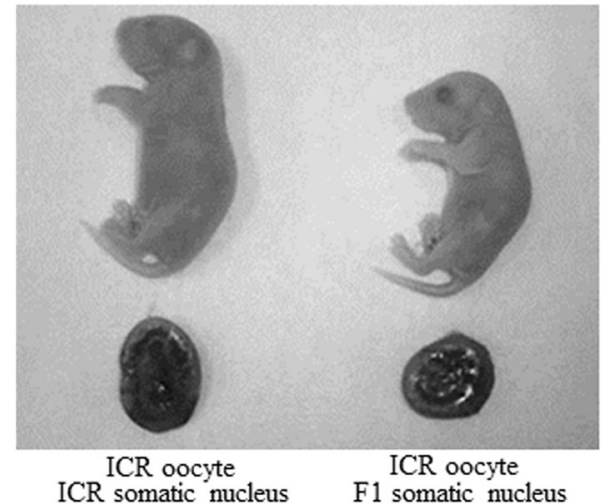

B

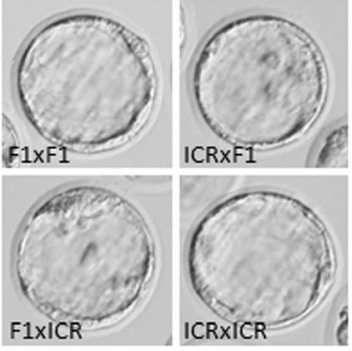

C

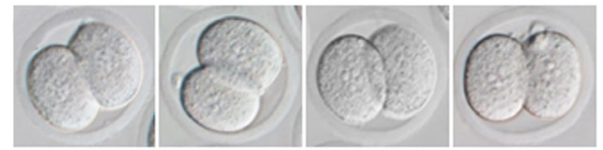

E

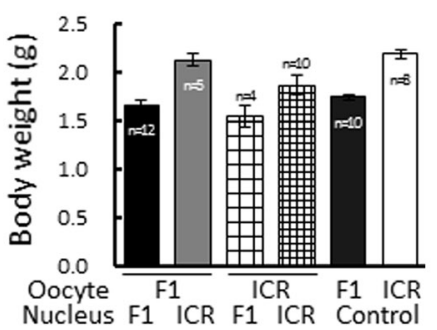

$\mathrm{F}$

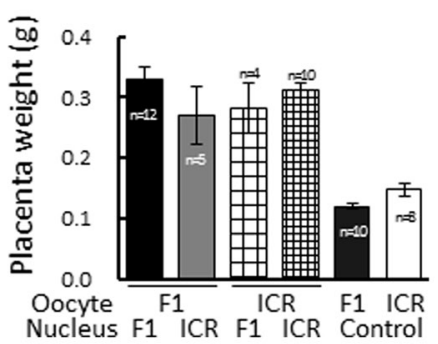

Figure 2 In vitro and full-term development of cloned embryos using ICR oocytes. (A) Developmental rates of cloned embryos at each stage. Observation was performed at 24,48 and $72 \mathrm{~h}$ after nuclear transfer. The rate of development to blastocysts was significantly decreased in ICR oocyte clones compared with that in F1 oocyte clones. (B) Blastocyst development in vitro. Blastocysts derived from F1 oocyte and F1 somatic nucleus (upper left), F1 oocyte and ICR somatic nucleus (lower left), ICR oocyte and F1 somatic nucleus (upper right) and ICR oocyte and ICR somatic nucleus (lower right). (C) Two-cell-stage cloned embryos. From left, F1 oocyte $\times$ F1 nucleus, F1 oocyte $\times$ ICR nucleus, ICR oocyte $\times$ F1 nucleus, and ICR oocyte $\times$ ICR nucleus. (D) Cloned offspring using ICR oocytes. Left: ICR oocyte $\times$ ICR somatic nucleus. Right: ICR oocyte $\times$ F1 somatic nucleus. (E) Average body weight of cloned mice. Clones from ICR somatic nuclei were always heavier than clones from F1 somatic nuclei, irrespective of the oocyte donor. (F) Average placental weight of cloned mice, which did not differ depending on the donor or oocyte strain. 
Table 3 Full-term development of cloned embryos using ICR oocytes.

\begin{tabular}{|c|c|c|c|c|c|c|c|c|}
\hline \multicolumn{2}{|c|}{ Mouse strain } & \multirow{2}{*}{$\begin{array}{c}\text { No. of } \\
\text { enucleated } \\
\text { oocytes }\end{array}$} & \multirow{2}{*}{$\begin{array}{l}\text { No. of oocytes } \\
\text { surviving after } \\
\text { injection }(\%)\end{array}$} & \multirow[t]{2}{*}{$\begin{array}{c}\text { No. of } \\
\text { oocytes } \\
\text { surviving } \\
\text { after } \\
\text { activation } \\
(\%)\end{array}$} & \multirow{2}{*}{$\begin{array}{c}\text { No. of oocytes } \\
\text { with PN formed } \\
(\%)\end{array}$} & \multirow{2}{*}{$\begin{array}{c}\text { No. of embryos } \\
\text { developed to } \\
\text { two-cell stage } \\
(\%)^{*}\end{array}$} & \multirow{2}{*}{$\begin{array}{l}\text { No. of } \\
\text { embryos } \\
\text { transferred } \\
\text { (recipient) }\end{array}$} & \multirow{2}{*}{$\begin{array}{l}\text { No. of } \\
\text { cloned } \\
\text { offspring } \\
(\%)^{* *}\end{array}$} \\
\hline Oocyte & Nucleus & & & & & & & \\
\hline BDF1 & BDF1 & 384 & 306 (79.7) & 299 (97.7) & $284(95.0)$ & $254(89.4)$ & $249(17)$ & $8(3.2)$ \\
\hline BDF1 & ICR & 391 & $324(82.9)$ & 317 (97.8) & 297 (93.0) & $258(86.9)$ & $258(17)$ & $5(1.9)$ \\
\hline Subtotal & & 775 & $630(81.3)^{\mathrm{a}}$ & $616(97.8)$ & $581(94.3)$ & $512(88.1)$ & 507 (34) & $13(2.6)$ \\
\hline ICR & BDF1 & 457 & 324 (70.9) & 316 (97.5) & $294(93.0)$ & $228(77.6)$ & $228(16)$ & $2(0.9)$ \\
\hline ICR & ICR & 748 & $548(73.3)$ & $527(96.2)$ & $492(93.4)$ & $410(83.3)$ & $393(26)$ & $10(2.6)$ \\
\hline Subtotal & & 1205 & $872(72.4)^{b}$ & $843(96.7)$ & $786(93.2)$ & $638(81.2)$ & $621(42)$ & 12 (1.9) \\
\hline BDF1 & BD129 & 144 & $131(90.1)$ & 127 (96.9) & $124(97.6)$ & $113(91.1)$ & $103(6)$ & $14(13.6)$ \\
\hline ICR & BD129 & 315 & $216(68.6)$ & $213(98.6)$ & $200(93.9)$ & 179 (89.5) & $179(9)$ & $11(6.1)$ \\
\hline
\end{tabular}

a vs b: $P<0.05$.

*Percentages relative to no. of embryos with PN developed. **Percentages relative to no. of embryos transferred.

PN: pronucleus.

of cloned offspring obtained using the ICR strain as the source of the recipient oocytes and those obtained using F1 strain as the source. Moreover, placenta weight demonstrated no relationship with donor or oocyte strain $(0.25 \mathrm{~g}-0.33 \mathrm{~g}$ in all cases); however, for all donor and oocyte combinations, the cloned mice exhibited specific abnormalities (hypertrophic placenta: placentomegaly), and the placenta was two to three times heavier than that of control-fertilized offspring $(0.12 \mathrm{~g}-0.15 \mathrm{~g})$. Note that in this study, we used the ICR strain as a surrogate mother and obtained ICR clones from ICR oocytes. Thus, we could not demonstrate the success of cloning by coat color. However, placentomegaly could be used to demonstrate the success of mouse cloning because this phenomenon never occurs in normally fertilized offspring (Wakayama \& Yanagimachi 1999).

\section{Discussion}

In this study, we focused on whether cloned mice can be obtained using oocytes derived from an ICR-outbred strain because, to date, all clones have been produced using F1 mouse oocytes (Wakayama \& Yanagimachi 2001, Gao et al. 2003, Inoue et al. 2003). The results demonstrated that oocytes from the ICR strain can be used as a substitute for those from an F1 strain to produce cloned mice if appropriate conditions are applied.

The survival rate on nuclear injection of ICR oocytes was slightly lower than that on nuclear injection of F1 oocytes. This might be an inherent feature of this strain's oocytes because, even with ICSI, the survival rate was slightly lower on using ICR oocytes than on using F1 oocytes (data not shown). Pfeiffer et al. also reported that recovery from the stress of manipulation depends on the oocyte composition of strains (Pfeiffer et al. 2015). This reduction in the survival rate might be avoided using other nuclear transfer methods, such as electrofusion (Ogura et al. 2000) or Sendai virus fusion (Ono et al.
2001). Once reconstructed oocytes had survived nuclear injection, their subsequent response (activation and pronuclear formation) was almost the same as that of F1 oocytes.

The most striking difference between ICR and F1 oocytes was the developmental potential of the cloned embryos in vitro. When cloned embryos derived from ICR oocytes were cultured in vitro for 5 days, only approximately $30 \%$ of them developed to the blastocyst stage, whereas $>70 \%$ of the cloned embryos derived from F1 oocytes developed to blastocysts. Under our culture conditions, most ICR oocytes fertilized with ICR spermatozoa developed to blastocysts; therefore, this poor developmental potential was only observed in cloned embryos derived from ICR oocytes. However, interestingly, when these cloned embryos were transferred to the oviduct at the two-cell stage, the rate of full-term development was almost comparable to that of cloned embryos derived from F1 oocytes. In this context, the following question arises: How can cloned embryos derived from ICR oocytes develop in vivo but not in vitro?

In general, when in vitro-fertilized embryos were transferred to the oviduct at the two-cell stage, the rate of successfully producing offspring was better than that by uterus transfer at the morula/blastocyst stage for which culture was performed for 4 days in vitro (Terashita et al. 2011, Itoi et al. 2012). In addition, it was previously difficult to culture ICR embryos in vitro because of the 'two-cell block', which never occurred in vivo. Although this blocking phenomenon was abolished by improving the culture medium (Chatot et al. 1990), the medium was developed only for fertilized embryos and not for cloned ones, and it is known that the optimal culture conditions differ between fertilized and cloned embryos (Gao et al. 2004, Boiani et al. 2005). These results suggested that even when using the CZB medium, the in vitro culture conditions of cloned embryos derived from 
ICR oocytes are less optimal than those in vivo or that ICR oocyte clones were more sensitive and fragile than fertilized ICR embryos.

Another difference is the CLS formation in cloned embryos derived from ICR oocytes, including that in nearly half of the one-cell-cloned embryos, which did not occur in cloned embryos derived from F1 oocytes and normally fertilized ICR oocytes. Our experiment demonstrated that CLS formation occurred when ICR oocytes were parthenogenetically activated. At present, the mechanism underlying CLS formation is not clear, but it cannot be ruled out that artificial oocyte activation for the ICR strain causes unknown damage to the embryos. This may reduce embryo quality and decrease the developmental rate in vitro. If this is the case, we must improve the oocyte activation methods to more natural methods, such as activation by spermatozoa (Kishikawa et al. 1999). These differences suggested that further research using ICR oocytes is required.

Importantly, when ICR oocyte clones at the two-cell stage were transferred to the oviduct, the birth rate of cloned offspring was relatively similar to that of $\mathrm{F} 1$ oocyte clones, irrespective of the nuclear donor strain. Both clones showed placentomegaly, which was an abnormal phenotype specific to cloned mice. Thus, even when clones were generated using ICR oocytes, the obtained offspring were comparable to typical clones derived from F1 oocytes, which suggested that the ICR strain can be used as a substitute for the F1 strain as an oocyte supplier. In this study, we used TSA and Latrunculin A, which were not used in the original mouse cloning method (Wakayama et al. 1998). TSA enhanced epigenetic modification (Kishigami et al. 2006) and LatA reduced cytotoxicity during the nuclear transfer procedure (Terashita et al. 2012). These factors may also have contributed to the success of ICR cloning.

The ICR strain is used worldwide and is usually cheaper than other mouse strains, costing nearly half the price of F1 or inbred strains. Therefore, the cost of mouse cloning experiments will be reduced if the ICR strain is used. In addition, if different strains' oocytes are used, factors for the reprogramming of oocyte cytoplasm will be compared between those different strains, which may provide an insight to help us identify the most important factors for reprogramming.

\section{Declaration of interest}

The authors declare that there is no conflict of interest that could be perceived as prejudicing the impartiality of the research reported.

\section{Funding}

This research did not receive any specific grant from any funding agency in the public, commercial or not-for-profit sector.

\section{Acknowledgements}

The authors thank $\mathrm{K}$ Kishida for assistance in preparing this manuscript. This work was partially funded by the Japan Society for the Promotion of Science to S K (26450458) and T W (16H02593); the Naito Foundation to S W; PRESTO of the Japan Science and Technology Agency to S K; Asada Science Foundation to TW; and the Takeda Science Foundation to TW. The authors would also like to thank Enago (www.enago.jp) for the English language review.

\section{References}

Boiani M, Eckardt S, Leu NA, Scholer HR \& McLaughlin KJ 2003 Pluripotency deficit in clones overcome by clone-clone aggregation: epigenetic complementation? EMBO Journal 22 5304-5312. (doi:10.1093/emboj/cdg507)

Boiani M, Gentile L, Gambles VV, Cavaleri F, Redi CA \& Scholer HR 2005 Variable reprogramming of the pluripotent stem cell marker Oct4 in mouse clones: distinct developmental potentials in different culture environments. Stem Cells 23 1089-1104. (doi:10.1634/ stemcells.2004-0352)

Chatot CL, Lewis JL, Torres I \& Ziomek CA 1990 Development of 1-cell embryos from different strains of mice in CZB medium. Biology of Reproduction 42 432-440. (doi:10.1095/biolreprod42.3.432)

Gao S, Czirr E, Chung YG, Han Z \& Latham KE 2004 Genetic variation in oocyte phenotype revealed through parthenogenesis and cloning: correlation with differences in pronuclear epigenetic modification. Biology of Reproduction 70 1162-1170. (doi:10.1095/ biolreprod.103.024216)

Gao S, McGarry M, Priddle H, Ferrier T, Gasparrini B, Fletcher J, Harkness L, De Sousa P, McWhir J \& Wilmut I 2003 Effects of donor oocytes and culture conditions on development of cloned mice embryos. Molecular Reproduction and Development 66 126-133. (doi:10.1002/ mrd.10300)

Inoue K, Ogonuki N, Mochida K, Yamamoto Y, Takano K, Kohda T, Ishino F \& Ogura A 2003 Effects of donor cell type and genotype on the efficiency of mouse somatic cell cloning. Biology of Reproduction 69 1394-1400. (doi:10.1095/biolreprod.103.017731)

Itoi F, Tokoro M, Terashita Y, Yamagata K, Fukunaga N, Asada Y \& Wakayama T 2012 Offspring from mouse embryos developed using a simple incubator-free culture system with a deoxidizing agent. PLOS ONE 7 e47512. (doi:10.1371/journal.pone.0047512)

Kimura Y \& Yanagimachi R 1995 Intracytoplasmic sperm injection in the mouse. Biology of Reproduction 52 709-720. (doi:10.1095/ biolreprod52.4.709)

Kishigami S, Mizutani E, Ohta H, Hikichi T, Thuan NV, Wakayama S, Bui HT \& Wakayama T 2006 Significant improvement of mouse cloning technique by treatment with trichostatin A after somatic nuclear transfer. Biochemical and Biophysical Research Communications 340 183-189. (doi:10.1016/j.bbrc.2005.11.164)

Kishigami S, Bui HT, Wakayama S, Tokunaga K, Van Thuan N, Hikichi T, Mizutani E, Ohta H, Suetsugu R, Sata T et al. 2007 Successful mouse cloning of an outbred strain by trichostatin A treatment after somatic nuclear transfer. Journal of Reproduction and Development 53 165-170. (doi:10.1262/jrd.18098)

Kishikawa H, Wakayama T \& Yanagimachi R 1999 Comparison of oocyte-activating agents for mouse cloning. Cloning $\mathbf{1} 153-159$. (doi:10.1089/15204559950019915)

Kuwayama H, Tanabe Y, Wakayama T \& Kishigami S 2017 Birth of cloned mice from vaginal smear cells after somatic cell nuclear transfer. Theriogenology 94 79-85. (doi:10.1016/j.theriogenology.2017.02.012)

Latham KE 1994 Strain-specific differences in mouse oocytes and their contributions to epigenetic inheritance. Development 120 3419-3426.

Ma JY, Li M, Luo YB, Song S, Tian D, Yang J, Zhang B, Hou Y, Schatten H, Liu Z et al. 2013 Maternal factors required for oocyte developmental competence in mice: transcriptome analysis of non-surrounded nucleolus (NSN) and surrounded nucleolus (SN) oocytes. Cell Cycle 12 1928-1938. (doi:10.4161/cc.24991) 
Mizutani E, Torikai K, Wakayama S, Nagatomo H, Ohinata Y, Kishigami S \& Wakayama T 2016 Generation of cloned mice and nuclear transfer embryonic stem cell lines from urine-derived cells. Scientific Reports $\mathbf{6}$ 23808. (doi:10.1038/srep23808)

Ogura A, Inoue K, Takano K, Wakayama T \& Yanagimachi R 2000 Birth of mice after nuclear transfer by electrofusion using tail tip cells. Molecular Reproduction and Development 57 55-59. (doi:10.1002/10982795(200009)57:1<55::AID-MRD8>3.0.CO;2-W)

Ono Y, Shimozawa N, Ito M \& Kono T 2001 Cloned mice from fetal fibroblast cells arrested at metaphase by a serial nuclear transfer. Biology of Reproduction 64 44-50. (doi:10.1095/biolreprod64.1.44)

Ono T, Li C, Mizutani E, Terashita Y, Yamagata K \& Wakayama T 2010 Inhibition of class IIb histone deacetylase significantly improves cloning efficiency in mice. Biology of Reproduction 83 929-937. (doi:10.1095/ biolreprod.110.085282)

Pfeiffer MJ, Siatkowski M, Paudel Y, Balbach ST, Baeumer N, Crosetto N, Drexler HC, Fuellen G \& Boiani M 2011 Proteomic analysis of mouse oocytes reveals 28 candidate factors of the "reprogrammome". Journal of Proteome Research 10 2140-2153. (doi:10.1021/pr100706k)

Pfeiffer MJ, Taher L, Drexler H, Suzuki Y, Makalowski W, Schwarzer C, Wang B, Fuellen G \& Boiani M 2015 Differences in embryo quality are associated with differences in oocyte composition: a proteomic study in inbred mice. Proteomics 15 675-687. (doi:10.1002/pmic.201400334)

Terashita Y, Li C, Yamagata K, Sato E \& Wakayama T 2011 Effect of fluorescent mercury light irradiation on in vitro and in vivo development of mouse oocytes after parthenogenetic activation or sperm microinjection. Journal of Reproduction and Development.57 564-571.

Terashita Y, Wakayama S, Yamagata K, Li C, Sato E \& Wakayama T 2012 Latrunculin a can improve the birth rate of cloned mice and simplify the nuclear transfer protocol by gently inhibiting actin polymerization. Biology of Reproduction 86 180. (doi:10.1095/biolreprod.111.098764)

Terashita Y, Yamagata K, Tokoro M, Itoi F, Wakayama S, Li C, Sato E, Tanemura K \& Wakayama T 2013 Latrunculin a treatment prevents abnormal chromosome segregation for successful development of cloned embryos. PLOS ONE 8 e78380. (doi:10.1371/journal.pone.0078380)

Van Thuan N, Bui HT, Kim JH, Hikichi T, Wakayama S, Kishigami S, Mizutani E \& Wakayama T 2009 The histone deacetylase inhibitor scriptaid enhances nascent mRNA production and rescues full-term development in cloned inbred mice. Reproduction 138 309-317. (doi:10.1530/REP-08-0299)

Thuan NV, Kishigami S \& Wakayama T 2010 How to improve the success rate of mouse cloning technology. Journal of Reproduction and Development 56 20-30. (doi:10.1262/jrd.09-221A)
Wakayama T \& Yanagimachi R 1999 Cloning of male mice from adult tailtip cells. Nature Genetics 22 127-128. (doi:10.1038/9632)

Wakayama T \& Yanagimachi R 2001 Mouse cloning with nucleus donor cells of different age and type. Molecular Reproduction and Development 58 376-383. (doi:10.1002/1098-2795(20010401)58:4<376::AIDMRD4>3.0.CO;2-L)

Wakayama T, Perry AC, Zuccotti M, Johnson KR \& Yanagimachi R 1998 Full-term development of mice from enucleated oocytes injected with cumulus cell nuclei. Nature 394 369-374. (doi:10.1038/28615)

Wakayama S, Kohda T, Obokata H, Tokoro M, Li C, Terashita Y, Mizutani E, Nguyen VT, Kishigami S, Ishino F et al. 2013 Successful serial recloning in the mouse over multiple generations. Cell Stem Cell 12 293-297. (doi:10.1016/j.stem.2013.01.005)

Wakayama S, Tanabe Y, Nagatomo H, Mizutani E, Kishigami S \& Wakayama T 2016 Effect of long-term exposure of donor nuclei to the oocyte cytoplasm on production of cloned mice using serial nuclear transfer. Cell Reprogram 18 382-389. (doi:10.1089/cell.2016.0026)

Wang F, Kou Z, Zhang Y \& Gao S 2007 Dynamic reprogramming of histone acetylation and methylation in the first cell cycle of cloned mouse embryos. Biology of Reproduction 77 1007-1016. (doi:10.1095/ biolreprod.107.063149)

Wang S, Kou Z, Jing Z, Zhang Y, Guo X, Dong M, Wilmut I \& Gao S 2010 Proteome of mouse oocytes at different developmental stages. PNAS 107 17639-17644. (doi:10.1073/pnas.1013185107)

Wilmut I, Schnieke AE, McWhir J, Kind AJ \& Campbell KH 1997 Viable offspring derived from fetal and adult mammalian cells. Nature 385 810-813. (doi:10.1038/385810a0)

Yan X, Yu S, Lei A, Hua J, Chen F, Li L, Xie X, Yang X, Geng W \& Dou Z 2010 The four reprogramming factors and embryonic development in mice. Cell Reprogram 12 565-570. (doi:10.1089/cell.2010.0008)

Yang X, Smith SL, Tian XC, Lewin HA, Renard JP \& Wakayama T 2007 Nuclear reprogramming of cloned embryos and its implications for therapeutic cloning. Nature Genetics 39 295-302. (doi:10.1038/ng1973)

Date received 10 August 2017

First decision 2 September 2017

Revised manuscript received 26 September 2017

Accepted 29 September 2017 